\title{
Cross-sectional evaluation of the Bronchitis Severity Score in Egyptian children: A move to reduce antibiotics
}

E M I Moawad, MD; M A E Haron, MD; R M A Maher, MD; E A A Abdallah, MD; H Hussein, MD; N M Badawy, MD; M E A El-Rheem, MB BCh

Department of Paediatrics, Faculty of Medicine, Cairo University, Egypt

Correspondingauthor: E M I Moawad (eimanmoawad@yahoo.com,iman.moawad@kasralainy.edu.eg)

\begin{abstract}
Background. Despite evidence of limited benefit of antibiotics in acute bronchitis, most paediatric patients are prescribed them. Objectives. To assess the validity of the Bronchitis Severity Score (BSS) in assessing the clinical response to treatment of acute bronchitis, and determine whether clinical data and basic laboratory measurements can be used to guide antibiotic prescription.

Methods. We enrolled 200 patients (age range 6 months - 12 years) with clinically diagnosed acute bronchitis. They were divided into three groups according to age. All patients were evaluated three times during the bronchitis episode (days 0,5 and 7 ). The primary outcome measurement was the change in the BSS from day 0 to day 7.

Results. On the initial visit, the mean (standard deviation (SD)) BSS was 8.36 (2.6), indicating moderate severity of bronchitis. The mean BSS decreased to 4.03 (2.3) on day 5 and to 2.36 (1.45) on day 7 . Initial blood tests showed anaemia (80\%), leucocytosis (6\%), bandaemia (3\%) and lymphocytosis (52\%). Only four patients were positive for C-reactive protein, while the erythrocyte sedimentation rate was elevated in $98 \%$ of cases. There were significant correlations between bandaemia, fever grade $(p<0.001)$ and white blood cell count with clinical variables such as the presence of secretions on chest auscultation $(p<0.05)$ and toxic facies on general examination $(p<0.05)$.

Conclusions. Acute bronchitis in children is a self-limiting disease that does not require routine administration of antibiotics. The BSS is a simple and practical clinical scoring system that is useful in evaluating disease severity and monitoring disease resolution in acute bronchitis.

S Afr Med J 2017;107(4):342-345. DOI:10.7196/SAMJ.2017.v107i4.11428
\end{abstract}

Acute bronchitis accounts for $80 \%$ of lower respiratory tract infections (LRTIs), and despite evidence that antibiotics are of little or no benefit, up to $80 \%$ of patients are prescribed them.${ }^{[1]} \mathrm{A}$ high incidence of infectious diseases and frequent use of antibiotics are reported from low- and middle-income countries (LMICs), where resistant bacteria spread rapidly owing to factors such as overcrowding, poor sanitation and a warm, humid climate. ${ }^{[2-4]}$ Although acute bronchitis should be differentiated from more severe illness that may require antibiotics, including pneumonia, ${ }^{[5]}$ disease-focused solutions address the limited value of medical history-taking and physical examination in differentiating between pneumonia and self-limiting acute bronchitis. ${ }^{[6-8]}$ Moreover, diagnostic uncertainty has encouraged general practitioners to prescribe antibiotics, since routinely requesting a chest radiograph for patients with LRTIs is neither feasible nor appropriate in most primary care centres. ${ }^{[1]}$

Although several clinical scoring systems have been used to assess the severity of LRTIs and predict the patient's prognosis, very few have included management of acute bronchitis. ${ }^{[9]}$ The Bronchitis Severity Score (BSS), first described in 1996 by Haidvogl et al., ${ }^{[10]}$ is a clinical assessment scale based on physician-assessed items in conjunction with subjective feedback from the patient. It was designed to be used by primary healthcare practitioners to assess the clinical status of a patient with acute bronchitis at various points of time, i.e. baseline and follow-up visits.

\section{Objectives}

To assess the validity of the BSS in assessing the clinical response to treatment of acute bronchitis in Egyptian children; and to determine whether simple laboratory measurements would help to identify patients with acute bronchitis who need an antibiotic, and indicate the possibility of a bacterial cause of the bronchitis.

\section{Methods}

\section{Study setting and design}

We used a cross-sectional study design, with a convenience sample collected from the general paediatric outpatient clinic at a university hospital. From January to May 2009, 200 patients were included consecutively at their first consultation with the participating paediatricians. Individual duration of the study was 7 days. During this time, three visits were scheduled for each patient (day 0 , day 5 and day 7). Children aged 6 months - 12 years who had a clinically based diagnosis of acute bronchitis and a BSS of $\geq 5$ were eligible to participate in the study. Those who had received treatment with antibiotics during the 2 weeks prior to the first study visit, those with symptoms suggestive of other potential causes of cough, such as allergic rhinitis, sinusitis, recurrent wheezing or asthma, and those with serious medical comorbidities such as congenital malformations, immunodeficiencies and heart disease were excluded. Furthermore, eligible patients were not enrolled if their caregivers were unwilling or unable to participate or if they lived away from the study area, making follow-up impractical. Study participants were classified according to their age into three groups: group 1 (infants), group 2 (preschool children) and group 3 (middle childhood).

\section{Ethical considerations}

Ethics approval was granted by the Institutional Review Board of the New Children's Hospital (Abou el Reesh), the specialist paediatric hospital of Cairo University, before the study started (no reference number). Informed consent was obtained from all parents or patients' guardians before they were enrolled in the study. Verbal assent was obtained from patients aged $>7$ years. The study objectives and procedures were explained, and guardians were reassured about the confidentiality of the study data. 


\section{Study measurements}

A detailed history was taken in all cases, with special emphasis on fever, cough, associated symptoms (e.g. stridor, hoarseness of voice, wheezing and dyspnoea) and a history of smoking by family members. A thorough chest examination was performed to confirm the diagnosis and exclude similar conditions. The BSS measured cough, sputum, rales/ rhonchi, chest pain during coughing, and dyspnoea. Each of these features of acute bronchitis was scored by a well-trained doctor using a 5-point Likert rating scale ranging from 0 to $4(0=$ absent, $1=$ mild, $2=$ moderate, $3=$ severe, $4=$ very severe $)$. The overall BSS was graded as mild $(0-7)$, moderate $(8-14)$ and severe $(15-20)$.

\section{Laboratory investigations}

Full blood counts (FBCs) were performed on an ADVIA 60 Hematology Analyzer (Bayer Diagnostics, UK). C-reactive protein (CRP) was tested for using a CRP Latex Test Kit (Biotec Laboratories, UK). To measure the erythrocyte sedimentation rate (ESR), $2 \mathrm{~mL}$ of venous blood was collected according to the Westergren method into a tube containing $0.5 \mathrm{~mL}$ sodium citrate. Blood cultures and sensitivity testing, only for patients with a temperature of $\geq 39^{\circ} \mathrm{C}$, were done using a Bactec 9050 Blood Culture System (Becton Dickinson, USA).

No antibiotics were prescribed during the study period. The patients received symptomatic treatment in the form of antipyretics, cough medications and safe remedies. In patients who initially presented with highgrade fever, the FBC and ESR were repeated.

\section{Outcome measures}

The main outcome measure was the initial BSS on presentation and the change in the BSS after 7 days.

\section{Statistical analysis}

A standard computer program, SPSS for Windows, release 16.0 (SPSS Inc., USA), was used for data entry and analysis. All quantitative variables were expressed as means with standard deviations (SDs). The Kruskal-Wallis test was used to estimate differences in quantitative values, the $\chi^{2}$ test to compare the frequency of qualitative values among the different study groups, and Spearman's correlation test for correlating non-parametric variables. For all tests, $p<0.05$ was considered significant.

\section{Results}

The demographic characteristics of the participants are shown in Table 1. The mean age of the children was 4.1 years, with the majority aged 2 - 5 years (45\%). There were significantly more boys than girls $(p<0.02)$, with a male/female ratio of 1.3:1. Children living in suburban regions had a significantly increased incidence of acute bronchitis $(p<0.001)$.

\section{Initial visit (day 0 )}

Clinical features of the study participants on day 0 are summarised in Fig. 1 . Of the

Table 1. Demographic characteristics of the study population $(N=200)$

\begin{tabular}{ll}
\hline Characteristics & Patients, $\boldsymbol{n}(\%)$ \\
\hline Sex & $112(56.0)$ \\
$\quad$ Male & $88(44.0)$ \\
$\quad$ Female & \\
Age category & $46(23.0)$ \\
6 - 23 months (infants) & \\
2 - 5 years (preschool) & $90(45.0)$ \\
6 - 11 years (middle & $64(32.0)$ \\
childhood) & \\
Residence & \\
Urban & $42(21.0)$ \\
Suburban & $93(46.4)$ \\
Rural & $65(32.5)$
\end{tabular}

patients, 124 (62\%) were found to have an elevated temperature, with hyperthermia $\left(\geq 38.9^{\circ} \mathrm{C}\right)$ in 36 children (18\%) (Fig. 2). An acute cough was the main symptom in all cases, coughing being particularly severe in preschool children. A frequent dry, unproductive cough was reported in $72 \%$ of patients. Auscultation revealed rhonchi in 42 children (21\%).

Based on the BSS, $47 \%$ of patients had moderate disease activity on initial presentation, with a mean (SD) overall score of 8.36 (2.6) (Fig. 3), and 14\% of patients were classified as severe.

The results of blood tests on day 0 are set out in Table 2. At the initial visit, 12 children (6\%) had showed leucocytosis, 6 (3\%) bandaemia and $104(52 \%)$ lymphocytosis (Table 3 ). The ESR ranged from 8 to $45 \mathrm{~mm} / \mathrm{h}$, with a mean of 15.88 (7.9) $\mathrm{mm} / \mathrm{h}$. CRP was mildly elevated in four children, all in the infant group, with titres ranging from 6 to $12 \mathrm{mg} / \mathrm{L}$ (normal up to $4 \mathrm{mg} / \mathrm{L}$ ). Blood culture and sensitivity testing, done only for patients who presented with high-grade fever (4\%), revealed no growth.

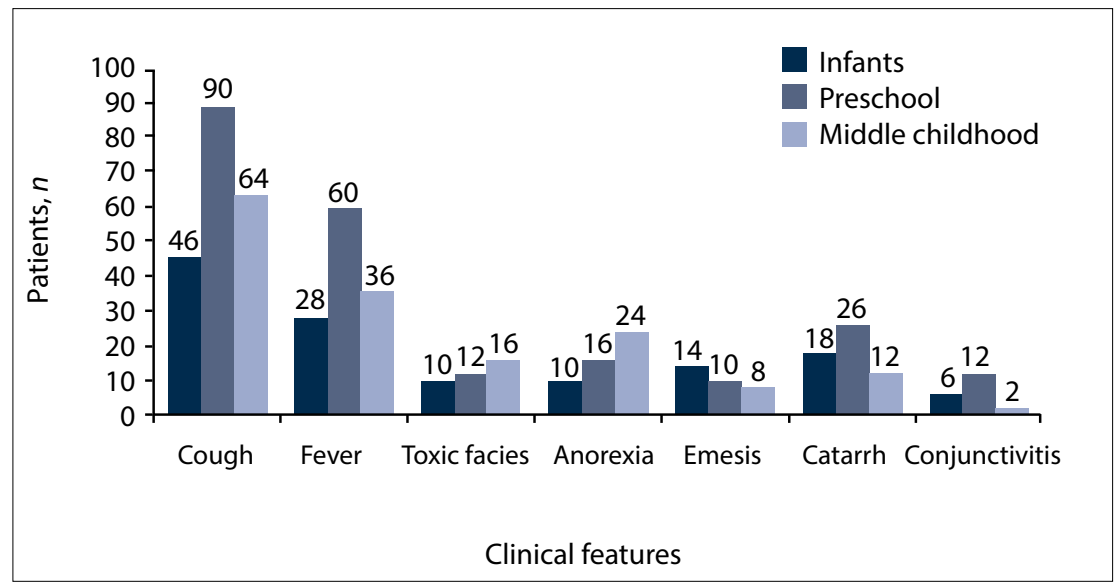

Fig. 1. Manifestations of acute bronchitis on initial presentation.

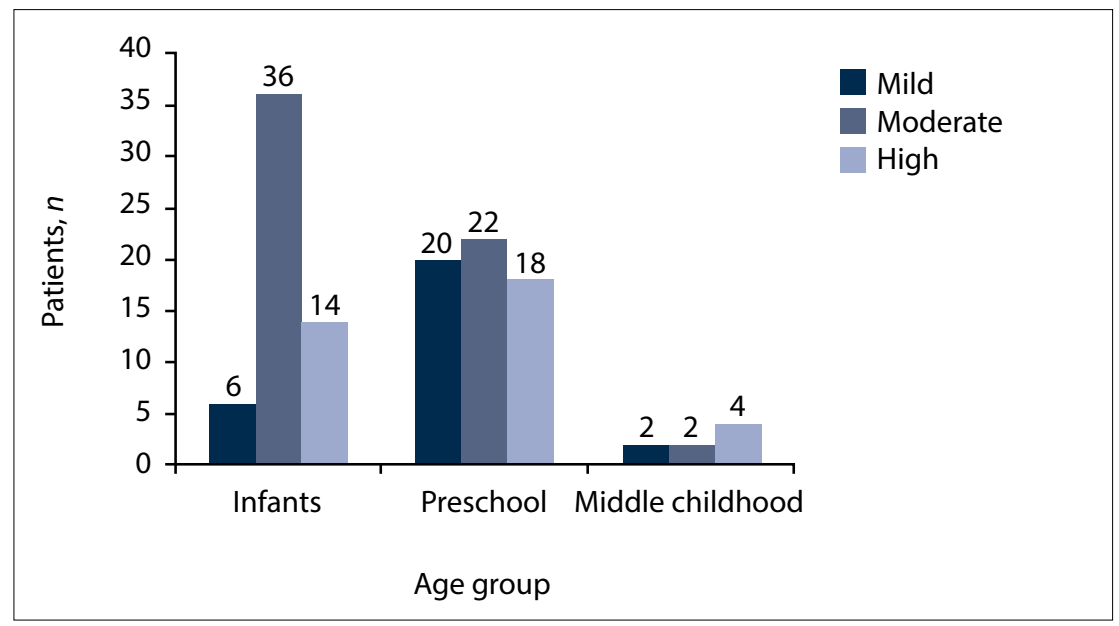

Fig. 2. Distribution of fever in the three age groups on initial presentation. 


\begin{tabular}{|c|c|c|c|}
\hline & $\begin{array}{l}\text { Infant } \\
(N=46)\end{array}$ & $\begin{array}{l}\text { Preschool } \\
(N=90)\end{array}$ & $\begin{array}{l}\text { Middle childhood } \\
(N=64)\end{array}$ \\
\hline \multicolumn{4}{|l|}{$\mathrm{Hb}(\mathrm{g} / \mathrm{dL})$} \\
\hline Normal range for age & $10.5-12.6$ & $11.5-12.5$ & $11.5-13.5$ \\
\hline Mean (SD) (range) & $9.9(1.2)(8-12)$ & $10.8(1.2)(8-13)$ & $11.0(1.4)(8-14)$ \\
\hline \multicolumn{4}{|c|}{ Total WBC count $\left(\times 10^{3} / \mu \mathrm{L}\right)$} \\
\hline Normal range for age & $6-17$ & $5-15.5$ & $4.5-13.5$ \\
\hline Mean (SD) (range) & $10.8(3.1)(5-16)$ & $9.2(3.3)(4-16)$ & $9.9(3.9)(5-18)$ \\
\hline \multicolumn{4}{|l|}{ Neutrophils (\%) } \\
\hline Normal range for age & $31-33$ & $33-51$ & $51-54$ \\
\hline Mean (SD) (range) & $35.9(11.2)(17-65)$ & $39.2(12.9)(12-72)$ & $43.3(17.1)(17-88)$ \\
\hline \multicolumn{4}{|l|}{ Lymphocytes (\%) } \\
\hline Normal range for age & $59-61$ & $42-59$ & $35-42$ \\
\hline Mean (SD) (range) & $53.6(12.2)(28-73)$ & $52.7(13.4)(23-75)$ & $47.3(16.9)(7-73)$ \\
\hline \multicolumn{4}{|c|}{ Band $/$ segmented $\left(\times 10^{3} / \mu \mathrm{L}\right)$} \\
\hline Normal range for age & $<0.2$ & $<0.2$ & $<0.2$ \\
\hline Mean (SD) & $0.05(0.04)$ & $0.05(0.04)$ & $0.04(0.04)$ \\
\hline
\end{tabular}

Table 3. Abnormal blood results in the three age groups on initial presentation

\begin{tabular}{|c|c|c|c|}
\hline & $\begin{array}{l}\text { Infant } \\
(N=46), \\
n(\%)\end{array}$ & $\begin{array}{l}\text { Preschool } \\
(N=90), \\
n(\%)\end{array}$ & $\begin{array}{l}\text { Middle childhood } \\
(N=64) \\
n(\%)\end{array}$ \\
\hline Anaemia $^{*}$ & $42(91.3)$ & $84(93.3)$ & $34(53.1)$ \\
\hline Leucocytosis $^{\dagger}$ & 0 & 0 & $12(18.8)$ \\
\hline Lymphocytosis & $14(30.4)$ & $44(48.9)$ & $46(71.9)$ \\
\hline Bandaemias & $2(4.3)$ & 0 & $4(6.2)$ \\
\hline \multicolumn{4}{|c|}{$\begin{array}{l}{ }^{*} \text { Haemoglobin: normal values } 10.5-12.6 \mathrm{~g} / \mathrm{dL} \text { for infants, } 11.5-12.5 \mathrm{~g} / \mathrm{dL} \text { preschool, } \\
11.5-13.5 \mathrm{~g} / \mathrm{dL} \text { middle childhood. } \\
\text { 'Total WBC count: normal values } 6-17 \times 10^{3} / \mu \mathrm{L} \text { for infants, } 5-15.5 \times 10^{3} / \mu \mathrm{L} \text { preschool, } \\
4.5-13.5 \times 10^{3} / \mu \mathrm{L} \text { middle childhood. } \\
\text { 'Lymphocytes: normal values } 9-61 \% \text { of total WBCs for infants, } 42-59 \% \text { preschool, } \\
35-42 \% \text { middle childhood. } \\
\text { 'Bandaemia: staff/segmented }<0.2 \text {. }\end{array}$} \\
\hline
\end{tabular}

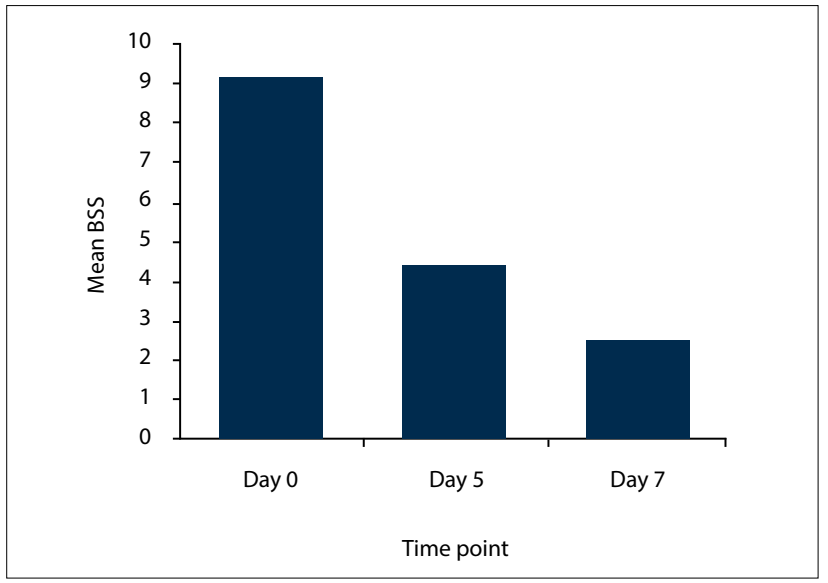

Fig. 3. Mean BSS at different time points (day 0, day 5, day 7).

\section{Primary outcome measures (day 5)}

The mean (SD) BSS decreased to $4.03(2.3)$ by the 5 th day of treatment (Fig. 3). A wet cough and discharge of mucus were reported in 38 patients (19\%), but the amount and frequency of sputum had decreased. The intensity of cough (day and night attacks) had decreased in 167 children (83.5\%). The individual signs of rales/rhonchi had improved in 23 patients $(11.5 \%)$. The fever had disappeared in 113 patients (56.5\%). No investigations were done at this visit.

\section{Secondary outcome measures (day 7)}

Final assessment on day 7 included BSS evaluation, and laboratory tests in selected cases. The mean (SD) BSS had decreased to 2.36 (1.45) (Fig. 3). The cough had completely disappeared in 132 patients $(66 \%)$, had improved with production of a small amount of whitish mucoid sputum in 13 (6.5\%), and was mild/dry in 55 (27.5\%). On clinical examination, the fever had disappeared in all previously feverish patients. Rhonchi, audible in only three children, were associated with a mildly productive cough.

Blood tests showed normalisation of the number of lymphocytes and neutrophils and of the ESR in patients who had initially presented with hyperthermia.

\section{Discussion}

Our study confirmed that the diagnosis of acute bronchitis is influenced by variables such as cough, purulent sputum and the presence of abnormal chest findings on examination. Overall, our results are consistent with previously published research on childhood acute bronchitis, ${ }^{[11]}$ with a predominance of acute cough in all cases. Twenty-eight percent of our participants had a productive cough with purulent sputum. These findings are consistent with other studies, ${ }^{[11,12]}$ in which $>50 \%$ of parents described the cough as dry, the remainder reporting it to be productive or of a mixed type. As has been reported by others, ${ }^{[13,14]}$ we found that the colour of the sputum had no predictive value for the diagnosis of bacterial bronchitis or for differentiating between pneumonia and bronchitis.

Although fever is unusual in patients with acute bronchitis, $62 \%$ of our patients were initially febrile. During follow-up, fever subsided in all cases without antimicrobial treatment. Similar results were observed in a previous study, ${ }^{[15]}$ where fever was reported in $66.6 \%$ of children. Further studies ${ }^{[16,17]}$ showed a $96.4 \%$ rate of remission of fever with only antipyretic treatment.

Consistent with other studies, ${ }^{[11,18]} 28 \%$ of our study participants, mainly preschool children, showed mild manifestations of upper 
respiratory tract infections (e.g. nasal discharge, pharyngitis, nasopharyngitis) during the initial visit.

Our study shows that the BSS is valuable as a simple index for scoring acute bronchitis in children. The mean BSS at the initial visit revealed moderate severity of bronchitis. This is consistent with the results of a previous study, ${ }^{[19]}$ where the mean (SD) BSS was 12 (1.5) ${ }^{[19]}$ By day 7, our mean BSS score had decreased to 2.36 (1.45). Similar results were reported from studies conducted in Ukraine and Germany. ${ }^{[20,21]}$

Investigations such as the total white blood cell (WBC) count, CRP and ESR have consistently been found to be one of the strongest determinants of antibiotic prescription. ${ }^{[21]}$ In a Japanese trial of outpatients with febrile acute bronchitis, measurement of WBCs was associated with a much lower rate of antibiotic prescription compared with usual care that depends only on clinical assessment. ${ }^{[22]} \mathrm{A}$ study in The Netherlands ${ }^{[1]}$ found that the use of CRP significantly reduced antibiotic prescription for LRTIs

In the present study, we were unable to establish significant correlations between the WBC count, CRP, ESR and the grade of fever $(p>0.05)$. This suggests that more studies are needed for better understanding of the context in which these investigations could be used to indicate whether an antibiotic is necessary.

In our study, even febrile children received only symptomatic treatment. Similar results were observed in a study carried out in Europe, ${ }^{[22]}$ where patients were divided into two groups. The first group received azithromycin, while the second group received lowdose vitamin C. Outcomes at days 3 and 7 showed no difference between two groups, with clinical improvement in $89 \%$ of cases.

To our knowledge, only a few studies ${ }^{[18,20]}$ have examined the validity of the BSS in assessing severity of acute bronchitis in children. Our findings are consistent with this previous research, which showed BSS to be a suitable index for use in children with acute bronchitis, including in LMICs.

\section{Study limitations}

Our study has a number of limitations, a major one being the validation of the BSS in the absence of a definite diagnosis of acute bronchitis. It was therefore difficult to evaluate the score in terms of sensitivity and specificity as regards clinical improvement or failure. Furthermore, all outcomes of the current study were subjective. Finally, the study was conducted in a single centre, where the study sample was not representative of the whole childhood population.

\section{Recommendations}

We identified the BSS as a simple and practical clinical scoring system useful in evaluating disease severity and monitoring disease resolution in acute bronchitis. It may therefore also help to decrease the injudicious use of antimicrobial agents and thereby combat antibiotic resistance. Our findings suggest that general practitioners and healthcare providers in primary healthcare units should be focused on in an effort to change their prescribing practices. Our findings also highlight the need for the development and implementation of national strategic plans to treat respiratory tract infections across all LMICs.

\section{Conclusions}

Acute bronchitis in children is a mild and self-limiting disease that rarely warrants antibiotic treatment. The most important condition to be ruled out before establishing the diagnosis of acute bronchitis is pneumonia. Increased awareness of the BSS will help in reducing unnecessary antibiotic prescription and thereby antimicrobial resistance. It should also be recognised that the presence of fever and/or coloured sputum is not an absolute indication of bacterial infection. Laboratory investigations and blood culture should be considered if a bacterial cause is suspected and supported by the clinical findings. Future research is needed to further validate the BSS.

Authorship. EMIM did the study design and field study, analysed the data, interpreted the results and wrote the article. MAEH conceived the study and participated in its design. RMAM conceived the study and participated in its design and co-ordination. EAAA, HH, NMB and MEAE-R examined the patients and did data entry. All the authors read and approved the final manuscript.

Funding. This research received no specific grant from any funding agency in the public, commercial or not-for-profit sectors.

Acknowledgements. We thank the paediatric outpatient clinic team and the clinical pathology laboratory staff of the New Children's Hospital, Cairo University.

1. Cals JWL, Butler CC, Hopstaken RM, Hood K, Dinant GJ. Effect of point of care testing for $\mathrm{C}$ reactive protein and training in communication skills on antibiotic use in lower respiratory tract infections: protein and training in consunication skils on antiotic use in lower respirat

2. Sharma M, Eriksson B, Marrone G, Dhaneria S, Lundborg CS. Antibiotic prescribing in two private . Sharma M, Eriksson B, Marrone G, Dhaneria S, Lundborg CS. Antibiotic prescribing in two private
sector hospitals; one teaching and one non-teaching: A cross-sectional study in Ujjain, India. BMC Infect Dis 2012;12:155. https://doi.org/10.1186/1471-2334-12-155

3. Kotwani A1, Wattal C, Joshi PC, Holloway K. Irrational use of antibiotics and role of the pharmacist: An insight from a qualitative study in New Delhi, India. J Clin Pharm Ther 2012;37(3):308-312. https:// doi.org/10.1111/j.1365-2710.2011.01293.x

4. Nordberg P, Stålsby LC, Tomson G. Consumers and providers - could they make better use of antibiotics? Int J Risk Saf Med 2005;17(3):117-125.

Gonzales R, Bartlett JG, Besser RE, et al. Principles of appropriate antibiotic use for treatment of uncomplicated acute bronchitis: Background. Ann Intern Med 2001;134(6):521-529. https://doi. org/10.7326/0003-4819-134-6-200103200-00021

6. Fischer T, Fischer S, Kochen MM, Hummers-Pradier E. Influence of patient symptoms and physical findings on general practitioners' treatment of respiratory tract infections: A direct observation study. BMC Fam Pract 2005;6:6. https://doi.org/10.1186/1471-2296-6-6

7. Hopstaken RM, Muris JWM, Knottnerus JA, Kester AD, Rinkens PE, Dinant GJ. Contributions of Hopstaken RM, Muris JWM, Knottnerus JA, Kester AD, Rinkens PE, Dinant GJ. Contributions of
symptoms, signs, erythrocyte sedimentation rate and C-reactive protein to a diagnosis of pneumonia in acute lower respiratory tract infection. Br J Gen Pract 2003;53(490):358-364.

in acute lower respiratory tract infection. Br J Gen Pract 2003;53(490):358-364.
Mwachari C, Nduba V, Nguti R, Park DR, Sanguli L, Cohen CR. Validation of a new clinical scoring system for acute bronchitis. Int J Tuberc Lung Dis 2007;11(11):1253-1259.

9. Margolis P, Gadomski A. Does this infant have pneumonia? JAMA 1998;279(4):308-313. https://doi. org/10.1001/jama.279.4.308

10. Haidvogl M, Schuster R, Heger M. Akute Bronchitis im Kindesalter. Multicenter-Studie zur Wirksamkeit und Vertraglichkeit des Phytotherapeutikums Umckaloabo. Z Phytother 1996;17(5):300313 .

1. Smith S, Fahey T, Smucny J, Becker LA. Antibiotics for acute bronchitis. Cochrane Database Syst Rev 2014, Issue 3. Art. No.: CD000245. https://doi.org/10.1002/14651858.CD000245.pub3

2. Wenzel RP, Fowler III AA. Acute bronchitis. N Engl J Med 2006;355(20):2125-2130. https://doi. org/10.1056/NEJMcp061493

13. Altiner $A$, Wilm $S$, Daubener $W$, et al. Sputum colour for diagnosis of a bacterial infection in patients with acute cough. Scand J Prim Health Care 2009;27(2):70-73. https://doi.org/10.1080/02813430902759663

14. Esposito S, Bosis S, Faelli N, et al. Role of atypical bacteria and azithromycin therapy for children Esposito S, Bosis S, Faelli N, et al. Role of atypical bacteria and azithromycin therapy for children
with recurrent respiratory tract infections. Pediatr Infect Dis J 2005;24(5):438-444. https://doi. with recurrent respiratory tract infections.

15. Braman S. Postinfectious cough: ACCP evidence-based clinical practice guidelines. Chest 2006;129(1 Suppl):138-146. https://doi.org/10.1378/chest.129.1_suppl.138S

16. Matthys H, Funk P. EPs 7630 improves acute bronchitic symptoms and shortens time to remission. Results of a randomized, double-blind, placebo-controlled, multicentre trial. Planta Med 2008;47(6):686692. https://doi.org/10.1055/s-2008-1074519

17. Matthys H, Kamin W, Funk P, Heger M. Pelargonium sidoides preparation (EPs 7630) in the treatment of acute bronchitis in adults and children. Phytomedicine 2007;14(Suppl 6):69-73. https://doi. org/10.1016/j.phymed.2006.11.015

18. Chuchalin AG, Berman B, Lehmacher W. Treatment of acute bronchitis in adults with a Pelargonium sidoides preparation $\left(\mathrm{EPs}^{*} 7630\right)$ : A randomized, double-blind, placebo-controlled trial. Explore 2005;1(6):437-445. https://doi.org/10.1016/j.explore.2005.08.009

19. Kamin W, Maydannik VG, Malek FA, Kieser M. Efficacy and tolerability of EPs 7630 in patients (aged 9. Kamin W, Maydannik VG, Malek FA, Kieser M. Efficacy and tolerability of EPs 7630 in patients (aged
6 - 18 years old) with acute bronchitis: A randomized, double-blind, placebo-controlled clinical dosefinding study. Acta Paediatr 2010;99(4):537-543. https://doi.org/10.1111/j.1651-2227.2009.01656.x

20. Matthys H, Eisebitt T, Seith B, Heger M. Efficacy and safety of an extract of Pelargonium sidoides (EPs 7630) in adults with acute bronchitis. Phytomedicine 2003;10(Suppl 4):7-17. https://doi.
(a) org/10.1078/1433-187x-00308

21. Korppi M. Non-specific host response markers in the differentiation between pneumococcal and viral pneumonia: What is the most accurate combination? Pediatr Int 2004;46(5):545-550. https://doi. org/10.1111/j.1442-200x.2004.01947.x

22. Albrich WC, Monnet DL, Harbarth S. Antibiotic selection pressure and resistance in Streptococcus pneumoniae and Streptococcus pyogenes. Emerg Infect Dis 2004;10(3):514-517.

Accepted 1 December 2016 